\title{
Including Psychosocial Factors in Screening for Surgery: A Preliminary Literature Review from a Social Work Perspective
}

Kym Frances Cranstoun, BSW, BA.

Social Work Department, Princess Alexandra Hospital, Metro South Health, Queensland

Rowanne Emma Wright, BSW, BSc.

Social Work Department, Princess Alexandra Hospital, Metro South Health, Queensland

Pim Kuipers, BA (Hons), MA, PhD. (Corresponding Author)

Centre for Functioning and Health Research, Metro South Health, Queensland and

Hopkins Centre, Griffith University, Queensland

Received: January 11, 2018 Accepted: May 2, 2018 Published: May 5, 2018

doi:10.5296/ijsw.v5i1.12463 URL: http://doi.org/10.5296/ijsw.v5i1.12463

\begin{abstract}
Introduction: The area of psychosocial screening for surgery holds considerable potential for social work practice, but to date there is little clarity regarding tools or roles.

Methods: A practice-based scoping review was conducted by social workers to provide an overview of relevant issues. Articles were screened for alignment with the research question, as well as for quality and relevance. Of the 26 articles included, quality and relevance varied considerably.

Results: The review summarised key psychosocial factors, screening issues, intervention issues and organisational aspects in the literature. It elucidated the importance of psychosocial factors in the acute hospital setting and specifically in the case of surgery. While the review found that there were many tools associated with psycho-social screening, there was no consensus as to which tool was most appropriate. There appeared to be little connection between tools and potential interventions, or indeed little consensus on suitable interventions.
\end{abstract}


Conclusion: Reviewed articles suggested that appropriate psychosocial screening and intervention would result in considerable individual and systems benefits. This is an area that requires greater clarity and research investment from the social work profession.

Keywords: Social work, Surgery, Screening, Scoping review

\section{Introduction}

Beyond the obvious physical dimensions, surgery can be a major disruption, affecting multiple psychosocial dimensions of a person's life, which may in turn compromise the patient's ability to cope or may trigger or exacerbate psychosocial difficulties (Levenson, 2007). Conversely, psychosocial factors may have an influence on the surgical patient and their recovery. Psychosocial factors have been recognised as important considerations in the lead-up to surgery (Hamilton et al., 2017). Indeed psychological factors have been identified as predictors of surgical outcome (Mannion et al., 2007).

As both a consequence of surgery and a contributor to surgical outcome, psychosocial issues clearly have complex interactions with surgery. As a profession which acknowledges and supports patients with physical, psychiatric, psychological, emotional, social, environmental and contextual concerns, social workers are well positioned to respond to such complexity within hospital and health systems (Australian Association of Social Workers, 2014). Indeed, the role of social workers to provide psychosocial support prior to and after surgery is increasingly being acknowledged (Australian Association of Social Workers, 2014). Furthermore, the social work role is well placed in the multidisciplinary healthcare team to help coordinate the patient's treatment, through providing comprehensive assessment, appropriate social work intervention, as well as post-surgery recovery assistance, preparing the patient for discharge, and assisting return to home and community life (Craig et al., 2016).

While motivations for social work assistance in the acute healthcare setting can be wide-ranging, it is noteworthy that social workers can add value by facilitating the patient transition through the health system and by reducing health service demand (Australian Association of Social Workers, 2014). The patient's post-surgery transition through the healthcare system can be enhanced by social worker intervention to identify psychosocial issues, which may in turn impact on the patient's length of stay, level of coping and readiness for discharge home. In this regard, some have suggested that social workers should also apply their skills to the pre-surgery context to improve services to patients and contribute to greater service efficiency (Epstein et al., 1998).

Despite Social Workers having the necessary communication and intervention skills, there appears to be few clear frameworks or tools to facilitate and consolidate the work of social workers in this important area. For example, in the pre-admission phase, in which potential psychosocial issues might be most constructively considered and addressed, social workers would appear to have few measures or assessments, which may facilitate their work.

In other settings, social workers regularly conduct psychosocial assessments which take into consideration the patient's home environment, culture and availability of resources and their emotional and cognitive presentation (Maramaldi et al., 2014). Such assessments, which link social factors and the individual's thought and behaviour typically guide social work 
interventions as well as enrich team deliberations and actions (Maramaldi et al., 2014). If similar assessments were available for the surgery context, it would strengthen clinical practice, benefit the patient's overall well-being, and enhance the role of the social worker as an integral part of the multidisciplinary healthcare team.

In response, we undertook a literature review to consider the potential role of social workers and the use of psychosocial screening tools for surgical patients. The specific goal of this review was to explore the place of social work pre admission psychosocial screening for surgical patients as a potential precursor to implementing a psychosocial assessment tool at pre admission of the patient's journey.

\subsection{Aims}

The current scoping review was conducted as part of a research training project, involving and assisting practicing social work clinicians in research. The project's aims included to analyse relevant research on this issue, to identify key concepts in the literature, and specifically to explore the availability of suitable assessment tools for preadmission screening of surgical patients. The exploration also sought to identify key characteristics that may benefit the patient's journey through the healthcare system. It was also anticipated that this review might inform service delivery and planning in this area.

\subsection{Scoping Reviews}

An important means of establishing evidence in social work and in many related areas is conducting some form of review or overview of the literature (Rozas \& Klein, 2010). The method used in the current scoping review was adapted from established frameworks for conducting scoping reviews (Arksey \& O'Malley, 2005), emphasising narrative rather than systematic methods, and using a collaborative, group approach (Levac, Colquhoun, \& O'Brien, 2010).

Scoping reviews are surveys of the literature to identify key concepts, and describe the relevant information on a topic (Arksey \& O'Malley, 2005). Within the scoping review process, available literature within a defined set is identified through a bibliographic data base search, screened for alignment with the research question, summarized, analysed and interpreted.

Recognising that the available literature on the topic of psychosocial assessment for surgery was mixed, and from multiple sources, it was seen as beneficial to adapt the traditional scoping review methodology in this case, to include ranking for quality and relevance, so that higher quality and more clinically relevant studies could have prominence in the review (Ogilvie et al., 2008). Consequently it was determined that the methodology would also incorporate a rating of the quality and relevance of each included article, (Daudt, Van Mossel, $\&$ Scott, 2013).

Further, given that part of the aim of the project was shared learning, as outlined previously, the methods also included thematic analysis of literature as a collaborative process, to determine key issues. The review was conducted as a practice-based research initiative by social work practitioners (novice researchers) working with an experienced research mentor (Daudt et al., 2013). Such reviews have been used in a range of health and welfare settings, and found to be particularly useful for identifying available evidence and noting research 
gaps, particularly in complex or emerging areas (Anderson, Allen, Peckham, \& Goodwin, 2008; Arksey \& O'Malley, 2005).

\section{Methods}

We adapted and simplified a number of steps from existing frameworks (Arksey \& O'Malley, 2005), which are presented in diagram form (Figure 1). The research team met to discuss and identify review questions. The resulting questions were defined as follows. What is the place and potential of the social worker role in preadmission screening of surgical patients? Can suitable social work related assessment tools (or principles) for preadmission screening be identified?

Based on the review question, a number of search terms were considered and trial searches were undertaken on PubMed, PsycINFO, SocINDEX and CINAHL bibliographic databases. Results of each preliminary search were examined by the team and found to have many thousands of "hits" which largely pertained to medicine, psychology and nursing. Since this was a social work practice-based initiative, with busy clinicians conducting the review, it was agreed to specifically focus on the most pertinent, sociology / social work literature, so the SocINDEX database was chosen. The search terms are outlined in Table 1.

Table 1. Agreed search terms

\begin{tabular}{ll}
\hline Category & Search terms selected \\
\hline Primary Treatment Context & surg* \\
AND & AND \\
Discipline Context & social work or allied health \\
AND & AND \\
Target Concern & psychological or psychosocial or emotional \\
AND & AND \\
Strategy & screening or assessment \\
\hline
\end{tabular}

The search resulted in 76 "hits", and after removal of duplicates, the titles and abstracts of all 74 potentially relevant articles were read by two team members, who screened them for alignment with the research question. As noted in Figure 1, 42 articles were found not to be relevant to the question, since they did not pertain to the key topic areas of assessment, screening, surgery or social work. The remaining 32 articles were retrieved and downloaded; each was read by two team members independently. Six of these articles were found not be relevant, since at full read it was determined that the content of the article did not align with the key topic areas. There remained 26 articles which were independently read and summarised by two team members.

For each article, key points or findings that pertained to the research question were documented and ranked for quality and relevance (see Appendix 1). The quality of an article was determined predominately by the clarity of the aims of the research; the research method 


\section{Macrothink}

International Journal of Social Work

ISSN 2332-7278

2018, Vol. 5, No. 1

used; the presentation of results and findings; the subjective 'readability'; and whether the study linked with practice, policy and future research. Similarly, the relevance of an article was determined by the content of the article and relevance to the research question; the professional area the study focussed on; the context of the research being comparable to the practice setting and how useful the information in the article was to clinical practice. The key points were discussed to establish consensus on a final rating of quality and relevance for each article.

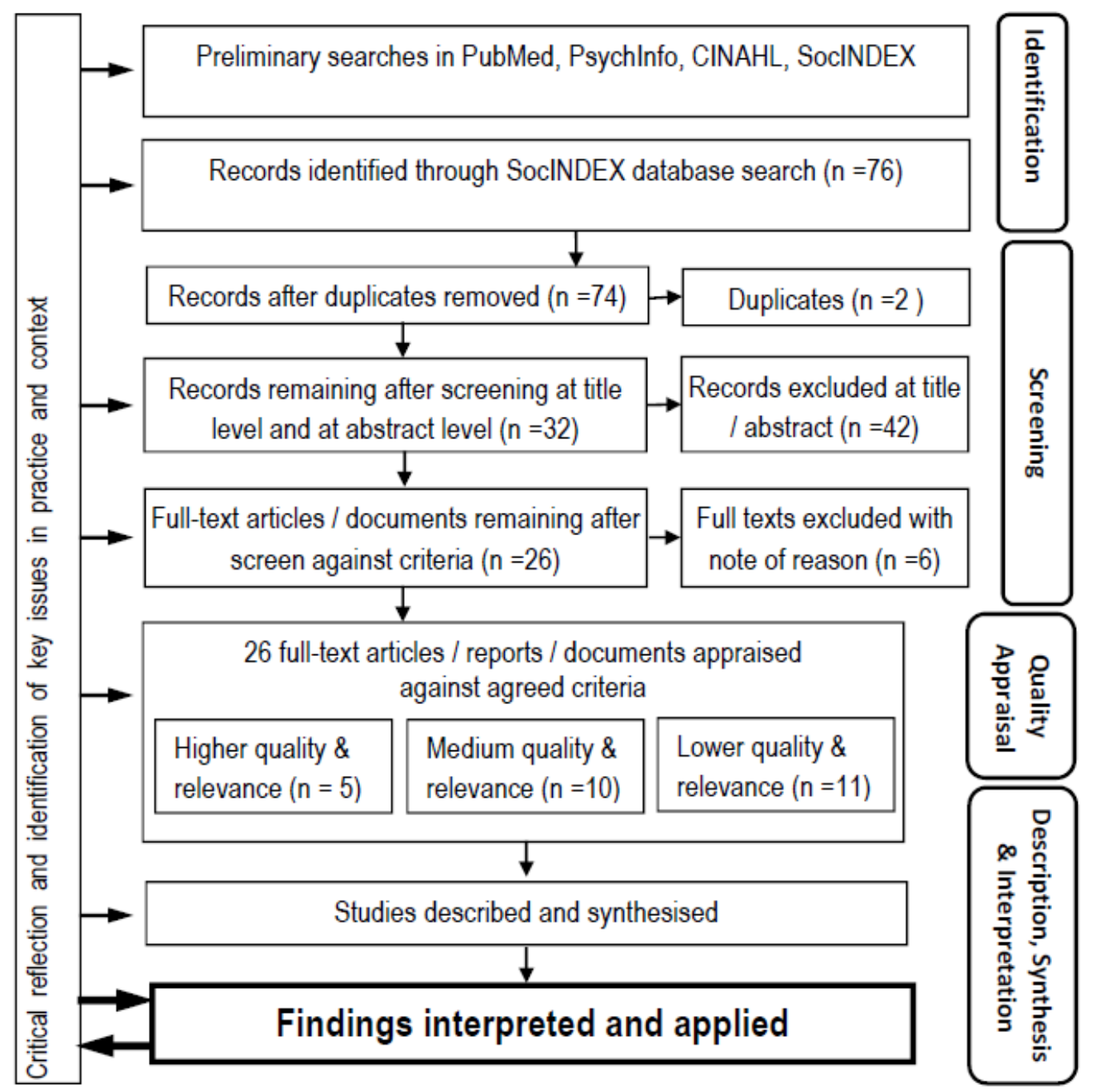

Figure 1. Flow diagram of the practice-based scoping review

Based on agreement, articles were then categorised at three levels of relevance and quality (Figure 1). Quality and relevance ratings were used in the analysis stage, giving weight to key points identified in the reviewed articles.

\section{Findings}

While social workers and other health professionals have recognised the important connection between psychosocial factors and positive hospital outcomes for many years 
(Querido, 1959), the current literature review found that the link between patients' psychosocial issues and hospital outcomes was not widely researched. In the studies reviewed, there was considerable emphasis on the link between psychosocial challenges and poor hospital and treatment outcomes, but without clear specificity. That is, challenges such as poor psychological adjustment, depression, anxiety, perceived loss of control, reduced coping ability, or cognitive impairments, were variously linked with longer hospital stays, reduced response to treatment, poorer recovery, more complications, more treatments, more invasive interventions, greater pain, and higher readmission rates (Drenth, 2013; Ensberg, Paletta, Galecki, Dacko, \& Fries, 1993; Fraczyk \& Godfrey, 2010; Lamarche, Taddeo, \& Pepler, 1998; Oxlad, Stubberfield, Stuklis, Edwards, \& Wade, 2006; Shahmansouri et al., 2014; Vallis \& Leddin, 2004).

However the current review found limited reference to the underlying origins of these challenges. The review also noted that while these challenges were predominately described as "psychological", it was clear that psychological dimensions of thoughts and behaviours are interrelated with social issues such as family engagement, social supports, community integration and social welfare. The review noted that it is particularly in such social issues that the social work profession is best placed to address. Hence, while general indications from these publications reflect the potential importance of this topic, the specific nature of the links was not well defined. Further, when these general indications were associated with the ranked quality and relevance of the articles, there were no clear patterns evident. In response, the current review sought to provide a meaningful thematic overview of key issues to establish greater clarity.

\subsection{Psychosocial Factors and Surgery}

The current review noted that psychosocial factors have been linked with the broader context and associated activities around surgery including hospital admission, general anaesthesia, and discharge (Eastwood, 1993; Mitchell, 2010). Indeed, even navigating the system prior to the point of surgery takes a significant psychological toll on the patient (Contrada et al., 2004; Rice, Mullin, \& Jarosz, 1992). More specifically, certain psychosocial dimensions were linked with surgery, these are noted below.

First, surgery has been described as a mechanistic process which limits meaningful communication (Mitchell, 2010). Surgery was noted as a major stressor (Rice et al., 1992), linked with anxiety and fear (Shahmansouri et al., 2014), which substantially affects mood (Elliott et al., 2010). The process of surgical treatment was described by reviewed articles as affecting a person's sense of control over their internal psychological environment and their subjective wellbeing (Halfens, 1995; Sørlie \& Sexton, 2004).

Second, regarding the influence of psychosocial factors, reviewed studies indicated that psychosocial issues as well as quality of life factors may impact the speed and nature of physical healing and recovery (Spilsbury et al., 2007). Specifically, the patient's health and wellbeing, mood state and social factors, such as the patient's home environment and formal and informal supports, can have a major influence over hospitalisation, healing and surgical outcomes (Elliott et al., 2010; Shahmansouri et al., 2014). Pre-surgery fear and anxiety have also been linked with post-operative depression, pain and poorer recovery (Contrada et al., 2004; Shahmansouri et al., 2014). 
Beyond the individual, the current scoping review also noted that the social and systemic supports around a person are also influential in cases of surgery. Early and prior family factors were seen as highly important (Contrada et al., 2004; Lamarche et al., 1998). Conversely, it was also noted that surgery can take a psychological toll on families, requiring greater supports and care (Contrada et al., 2004). Beyond the immediate family, the review found that surgery may have other social consequences, such as greater dependency on others (Eastwood, 1993). Factors of social support, social wellbeing, past experiences, social vulnerability and consultation with family and extended networks, were all recognised as important factors affecting length of stay and outcomes (de Jonge et al., 2000; Fraczyk \& Godfrey, 2010; Lamarche et al., 1998). Further, factors such as the need for a period of social adjustment were also noted as required after surgery (Danielsen \& Rosenberg, 2014). Interestingly the review found that issues of gender, age, and vulnerability affected patients' responsiveness to socially-oriented interventions (Preyde \& Chapman, 2007; Schoessler, 1989).

In summary and acknowledging the ranked quality and relevance of articles, four of the highly ranked articles emphasised the link between psychosocial issues, poorer treatment outcomes and longer hospital stays (Epstein et al., 1998; Preyde \& Chapman, 2007; Shahmansouri et al., 2014; Spilsbury et al., 2007). This underscored the importance of these connections. Other studies which informed this theme, while useful for general concept formation, were not ranked particularly highly for quality and relevance, due to methodological issues, contextual differences, and different professional areas of focus.

\subsection{Psychosocial Screening}

Psychosocial screening is an important aspect of social work practice. It includes an overview of the patient's history, as well as demographic, social, psychological, and medical factors. In light of the above, reviewed articles recommended specific psychosocial screening as a precursor for surgical treatment, and as a strategy for addressing length of stay (de Jonge et al., 2000). The review noted that psychosocial screening should include particular attention to key dimensions, which are influential in surgery. These include, age of the patient, co-morbidities, cognitive functioning, locus of control, mental health issues such as depression and anxiety (Halfens, 1995; Preyde \& Chapman, 2007), as well as coping skills, perceived medical symptoms, general life history, and healthcare history (de Jonge et al., 2000; Johansson, Salanterä, \& Katajisto, 2007; Oxlad et al., 2006; Preyde \& Chapman, 2007).

Importantly, from a social work perspective, the review also noted that screening should acknowledge the whole person rather than just their condition (Dear, 1985), and that the patient's social concerns should be a vital dimension of screening (de Jonge et al., 2000). Reviewed articles emphasised that early and comprehensive screening is important, particularly for the socially vulnerable (de Jonge et al., 2000). Screening is required as a basis for addressing length of stay (de Jonge et al., 2000), it can inform discharge planning and community follow up (Oxlad et al., 2006; Preyde \& Chapman, 2007), and it is a hallmark of a quality service (Epstein et al., 1998). It was noted that psychosocial screening should follow social work principles and seek to facilitate empathetic listening (Bennett, Legon, \& Zilberfein, 1990; Oxlad et al., 2006; Preyde \& Chapman, 2007). 
With reference to timing, there were indications that screening should take place prior to hospital admission (Gorton, Jayanthi, Lepping, \& Scriven, 2008), however in reality, the literature indicated that screening is mostly conducted on admission or post admission (within 3 days) (de Jonge et al., 2000; Epstein et al., 1998). Reviewed articles noted that for many patients, emotional, psychological and practical concerns are particularly pronounced on admission (Bennett et al., 1990), however the pre-surgical processes and procedures rarely accommodate such screening or responses to these concerns (Spilsbury et al., 2007).

Many of the 26 reviewed articles noted the use of specific screening instruments (Table 2). These included: Bypass Grafting Fear Scale, Spielberg State Anxiety Inventory, Depression and Anxiety Stress Scales, Posttraumatic Diagnostic Scale, Orthopaedic Patient Knowledge Questionnaire, Modified Empowerment Questionnaire, Index of Daily Living, OARS Instrumental and ADL battery, General Health Questionnaire, Geriatric Depression Scale, disease specific QOL measures, Stroop Task, Inflammatory Bowel Disease Questionnaire, Coping Responses Inventory, Implicit Models of Illness Questionnaire, The Life Stressors and Social Resources Inventory, and the Personal History Checklist for Adults. Despite this extensive array of screening tools, none was described or utilised by more than one reviewed study. There would appear to be little consensus on the best tools for such screening.

Further, while many of the identified screening tools included psychosocial dimensions, they had a strong focus on biomedical factors, and most were administered by nurses. Unfortunately in these settings nurses often have insufficient time to complete pre-admission tasks, despite such screening requiring considerable time and communication (Fraczyk \& Godfrey, 2010). Acknowledging the clear overlap between the focus of psychosocial screening and social work skills (Bennett et al., 1990; de Jonge et al., 2000; Epstein et al., 1998), it would appear that the staffing model for such screening warrants further consideration.

Interestingly, the review noted limited discussion of core practical matters in the articles regarding psychosocial screening. While a number of articles mentioned broader social concerns and community follow-up (de Jonge et al., 2000; Oxlad et al., 2006), practical issues such as the implications of surgery for physical recovery, return to work, pensions, benefits, family roles and home modifications were not discussed at length. While this may be a reflection of the potential diversity of surgical outcomes, it may also be a function of the articles included under the review criteria.

In summary, and noting the ranking of quality and relevance of articles, those articles which discussed elements of screening for psychosocial issues were of medium to higher quality and relevance. Likewise a study to develop a psychosocial assessment tool for classification of patients was ranked highly (Vallis \& Leddin, 2004), suggesting a potential foundation for such work. The review underlined the importance of psychosocial screening tools, for patient-related and hospital-related concerns; from patient outcome to hospital length of stay. However it was evident that there is not one clearly indicated measure for psychosocial patient concerns in surgical settings, and that practical concerns may require specific attention. Despite this, the review was able to identify a few key elements for development of such a screen. It was also noted that a number of the reviewed articles were over 10 years old, 
and while many are still relevant, this further underscores the need for current research in this area.

\subsection{Psychosocial Interventions}

Interventions which were described in the reviewed studies addressed a number of issues including fearfulness, anxiety, stressors, general mood and related concerns (Fraczyk \& Godfrey, 2010; Gilmartin, 2004; Rice et al., 1992). The types of intervention described included, information provision and enhancing knowledge (Gilmartin, 2004; Oxlad et al., 2006), providing psychological and social support (Gilmartin, 2004; Lamarche et al., 1998; Mitchell, 2010), teaching and self-instruction approaches (Rice et al., 1992), as well as enhancing the link between the patient and doctor (Fraczyk \& Godfrey, 2010). Strategies employed included telephone-based (Epstein et al., 1998; Lamarche et al., 1998), as well as face to face interventions (Gilmartin, 2004).

Table 2. Article characteristics

\begin{tabular}{|c|c|c|c|}
\hline Author and year & Method & Screening instruments noted & Perspective \\
\hline $\begin{array}{l}\text { Bennett et al } \\
(1989)\end{array}$ & Qualitative & Nil & Social Work \\
\hline $\begin{array}{l}\text { Contrada et al } \\
(2004)\end{array}$ & $\begin{array}{l}\text { Qualitative and } \\
\text { Quantitative }\end{array}$ & $\begin{array}{l}\text { Beck Depression Inventory } \\
\text { Life Orientation Test } \\
\text { Multidimensional Scale of } \\
\text { Perceived Social Support }\end{array}$ & Psychology \\
\hline Danielson (2014) & $\begin{array}{l}\text { Qualitative and } \\
\text { Quantitative }\end{array}$ & $\begin{array}{l}\text { Ostomy Adjustment Scale } \\
\text { Short form } 36 \text { v2 (Quality of } \\
\text { Life measure) }\end{array}$ & Nursing/medical \\
\hline Dear (1985) & Qualitative & Nil & $\begin{array}{l}\text { Patient } \\
\text { perspective }\end{array}$ \\
\hline Drenth (2013) & Qualitative & Nil & Social Work \\
\hline Eastwood (1993) & Quantitative & Nil & Nursing/medical \\
\hline Elliott et al (2010) & Quantitative & $\begin{array}{l}\text { Profile of Mood States } \\
\text { (POMS) }\end{array}$ & Nursing/medical \\
\hline $\begin{array}{l}\text { Ensberg et al } \\
(1993)\end{array}$ & Quantitative & Nil & Nursing/medical \\
\hline $\begin{array}{l}\text { Epstein et al } \\
(1998)\end{array}$ & $\begin{array}{l}\text { Qualitative and } \\
\text { Quantitative }\end{array}$ & $\begin{array}{l}\text { "Preadmission screening } \\
\text { instrument" } \\
\text { "Post discharge questionnaire" }\end{array}$ & Social Work \\
\hline $\begin{array}{l}\text { Fraczyk and } \\
\text { Godfrey (2010) }\end{array}$ & $\begin{array}{l}\text { Qualitative and } \\
\text { Quantitative }\end{array}$ & $\begin{array}{l}\text { Non-validated preoperative } \\
\text { assessment questionnaire }\end{array}$ & Nursing \\
\hline Gilmartin (2004) & Qualitative & Face-to-face interviews & Nursing \\
\hline
\end{tabular}


Gorton et al Qualitative (2008)

Halfens (1995) Qualitative

(2007)

Jonge et al (2000)
Qualitative and
Quantitative

Lamarche et al (1998)

Lepczyk et al Qualitative and (1990)

Mitchell (2010) Qualitative

$\begin{array}{ll}\text { Oxlad et al (2006) } & \text { Qualitative } \\ \text { Quantitative }\end{array}$

Quantitative

and
Questionnaire

Multidimensional

Locus of Control (Form A)

Orthopaedic

Patient

Knowledge Questionnaire

Modified Empowerment

Medical

Questionnaire

Nil

Psychiatry

Visual Analog Scale (anxiety

Qualitative and measure)

Coronary Artery Bypass Graft

Nursing

Knowledge Questionnaire

Background Questionnaire

Heart Surgery Questionnaire Nursing

State-Trait Anxiety Inventory

Nil

Nursing

Depression Anxiety Stress

Scales

Posttraumatic Diagnostic Scale

Psychology

Identification of Seniors at

Risk

Mini-Mental State Exam

Index of Activities of Daily

Preyde and Qualitative and Living

Chapman (2007) Quantitative

OARS

Instrumental ADL

Social Work

Battery

General Health Questionnaire

Geriatric Depression Scale

\begin{tabular}{|c|c|c|c|}
\hline Rice et al (1992) & $\begin{array}{l}\text { Qualitative and } \\
\text { Quantitative }\end{array}$ & Mood Adjective Checklist & Nursing \\
\hline Schoessler (1989) & $\begin{array}{l}\text { Qualitative and } \\
\text { Quantitative }\end{array}$ & Survey & Nursing \\
\hline Shahmansouri et & Qualitative & Bypass Grafting Fear Scale & Psychology and \\
\hline al (2013) & Quantitative & Spielberg & Nursing \\
\hline
\end{tabular}


Sorlie and Sexton (2004)

Quantitative

(2004)

Spilsbury et al (2007)

Vallis and Leddin (2004)
Quantitative
Inventory Questionnaire

Multidimensional Health

Locus of Control (Form A)

NEO-ffi (Personality traits)

Ways of Coping Questionnaire Psychiatry and Brief Symptom Inventory Medical

Global measure of physical functioning

SF-36 questionnaire

Semi-structured interviews Nursing

Stroop Task (Cognitive Style)

Inflammatory Bowel Disease

Questionnaire (Quality of Life

Measure)

Coping Responses Inventory

Implicit Models of Illness Psychology

Questionnaire

Life Stressors and Social

Resources Inventory

Personal History Checklist for

Adults

While it has been noted that without effective intervention, surgery patients may have substantial unmet psychosocial needs (Preyde \& Chapman, 2007), from the current review, the outcomes reported from such interventions were mixed. One study found that "preoperative patient teaching" had no significant effect, and had minimal impact on the patient's ability to cope with anxiety (Lepczyk, Raleigh, \& Rowley, 1990). A number of other studies however described interventions such as resulting in decreased length of stay and fewer bio-psychosocial risks (Epstein et al., 1998), a lower complication rate, increased patient satisfaction, enhanced coping, reduced stress, earlier return to work and return to activities of daily living (Rice et al., 1992; Schoessler, 1989).

It was noted that in many cases, the interventions described were quite limited. Some were purely educational or knowledge oriented, and did not have an explicit psychosocial component (Danielsen \& Rosenberg, 2014). As with the use of screening tools, a number of the described admission-related interventions appeared to be conducted from a nursing perspective. While such interventions may have included psychological aspects and achieved some system and patient outcomes (Rice et al., 1992), they are less likely to have focused on or emphasised psychosocial dimensions to the extent that would be apparent in a social work intervention. It was noteworthy that where a psychosocial dimension was included, it was the 
aspect seen as most beneficial and important by patients themselves (Schoessler, 1989). Other described features of successful psychosocial interventions which align with social work priorities included matching the intervention with the individual's needs and coping style (Gilmartin, 2004), and ensuring a highly patient centred approach (Fraczyk \& Godfrey, 2010).

While there are a few promising indications regarding psychosocial interventions, it should be noted that much of the reviewed literature was descriptive rather than experimental. As such there are few causal outcomes that can be drawn from the current review. Indeed, acknowledging the ranking of quality and relevance of articles, many of those studies which contributed information to this section on psychosocial interventions were ranked lower by the authors rating system. This suggests that the strength of evidence found pertaining to this aspect was not strong, and therefore the need for high quality intervention research is further underlined. There is a clear need for social work related research which clearly investigates such interventions against patient outcomes and quality of life as well as system outcomes, such as reduced length of stay.

Table 3. Summary of key points identified in the literature review

Psychosocial - There are multiple links between psychosocial factors and surgery.

Factors and - Psychological factors such as anxiety, fear, mood and stress are both Surgery consequences of surgery and also influential in surgical outcome and length of stay.

- Surgery may also impact on the person's social networks.

Psychosocial - Numerous psychosocial screening tools have been proposed for tis Screening setting, but none have been used consistently.

- Psychosocial screening might include evaluation of anxiety depression, coping skills, but must incorporate social dimensions and supports, look at the whole person and facilitate listening.

- This is an area that must be a key priority for future research.

Psychosocial - Despite the clear need for meaningful psychosocial interventions, those Interventions noted in the review were quite limited in scope

- Most were focused on the provision of information and knowledge about surgery.

- Where present, psychosocial aspects of interventions were highly valued and linked with positive outcomes (but not uniformly).

- The need for social work specific interventions is underlined.

Organisational - There are many potential systems and organisational benefits of $\&$ procedural psychosocial screening.

aspects

- Optimised admission and increased knowledge were identified as key

- Increased readiness for discharge and greater patient satisfaction were also noted 
3.4 Organisational and Procedural Aspects of Psychosocial Screening

The current review found that psychosocial issues may be overlooked against competing demands in traditional hospital structures and surgical procedures (Spilsbury et al., 2007), which may result in increased length of stay or other consequences. In light of fiscal constraints on services, and pressure to reduce length of stay (Bennett et al., 1990; Preyde \& Chapman, 2007), a greater focus on screening may be warranted. Indeed, with an ageing population (who may have multiple co-morbidities including depression, anxiety and greater severity of illness), there is a pronounced need to ensure optimal admission processes (Preyde \& Chapman, 2007).

Reviewed articles pointed to the organisational and procedural benefit of screening to identify psychosocial issues (Epstein et al., 1998; Lamarche et al., 1998). Screening was linked with a number of positive outcomes including increased patient satisfaction (Epstein et al., 1998; Fraczyk \& Godfrey, 2010), greater readiness for discharge, and increased knowledge about admission, surgery and recovery (Lamarche et al., 1998). Such outcomes assist in the surgical process and recovery, and keep the focus on patient centred care.

Importantly, the review noted the organisational benefit of identifying and addressing psychosocial factors early (Fraczyk \& Godfrey, 2010), to optimise hospital admission, ideally at pre-admission stages (Oxlad et al., 2006). When patients are better prepared for hospital admission, have greater awareness of hospital procedures, enhanced understanding of the nature of their surgical intervention, and realistic expectations of outcomes, the benefits are also likely to extend to organisational outcomes such as length of stay (Epstein et al., 1998; Fraczyk \& Godfrey, 2010; Lamarche et al., 1998; Oxlad et al., 2006). Further, the identification of psychosocial factors at pre-admission can facilitate referral to appropriate professionals which allows the focus of hospitalisation to be on the surgical procedure and recovery.

In summary, and acknowledging the ranking of quality and relevance of articles, it was again noted that articles pertaining to organisational and procedural aspects were of medium quality and relevance, and generally quite dated. Considering the competing demands in surgical settings (including physical recovery, fiscal constraints, etc), greater awareness and formal acknowledgement of psychosocial issues on admission is vital. The use of an appropriate screening tool will also ensure they can be recognised at an organisational level and that more patient-centred care can be achieved.

\section{Conclusion}

In acute hospital settings, psychosocial factors are clearly an influence on surgical outcomes and conversely they are highly influenced by the process of surgery and recovery. On the basis of the 26 articles reviewed, it would appear that while the area of psychosocial assessment prior to surgery holds considerable potential for meaningful social work engagement, substantial foundational work is still required to establish the process and detail of such screening and intervention. These findings are summarised in Table 3.

While the current scoping review has identified a number of important factors, it should be noted that they are not necessarily exhaustive, and that there were a number of limitations to the review. First, as a practice-based study let by social work practitioners, the database 
search was limited for pragmatic reasons. While this meant that not every potential source was included, it was mitigated by the selection of references from the most appropriate database. Second, the studies reviewed included descriptive studies, opinion pieces, surveys and service evaluations. As a result, they were difficult to compare and evaluate. In response, we chose a method, which integrated ratings of quality and relevance (Appendix 1) to enhance the relevance of our review process.

From the articles reviewed, it appears that considerable attention has been paid to providing patients with information prior to surgery, and some attention has been paid to purely psychological aspects of screening, the broader social and psychosocial dimensions have received less attention. While some professions such as nursing have focused on this area in general, it would appear that social work input is rare.

Based on the current review, it can be concluded that if such screening and intervention were developed and applied appropriately, patient well-being may be improved, physical and psychosocial outcomes may be enhanced. As a result, patients, families, professionals and services may benefit from improved patient trajectories through the system.

\section{References}

Anderson, S., Allen, P., Peckham, S., \& Goodwin, N. (2008). Asking the right questions: scoping studies in the commissioning of research on the organisation and delivery of health services. Health Res Policy Syst, 6(7), 1-12. https://doi.org/10.1186/1478-4505-6-7

Arksey, H., \& O'Malley, L. (2005). Scoping studies: towards a methodological framework. International journal of social research methodology, 8(1), 19-32. https://doi.org/10.1080/1364557032000119616

Australian Association of Social Workers. (2014). Scope of Social Work Practice in Health. Retrieved from www.aasw.asn.au/document/item/6423.pdf

Bennett, C. J., Legon, J., \& Zilberfein, F. (1990). The significance of empathy in current hospital based practice. Social Work in Health Care, 14(2), 27-41. https://doi.org/10.1300/J010v14n02_03

Contrada, R. J., Goyal, T. M., Cather, C., Rafalson, L., Idler, E. L., \& Krause, T. J. (2004). Psychosocial factors in outcomes of heart surgery: the impact of religious involvement and $\begin{array}{lllll}\text { depressive } \quad \text { symptoms. } & \text { Health }\end{array}$ https://doi.org/10.1037/0278-6133.23.3.227

Craig, S., Frankford, R., Allan, K., Williams, C., Schwartz, C., Yaworski, A., ... Malek-Saniee, S. (2016). Self-reported patient psychosocial needs in integrated primary health care: A role for social work in interdisciplinary teams. Social Work in Health Care, 55(1), 41-60. https://doi.org/10.1080/00981389.2015.1085483

Danielsen, A. K., \& Rosenberg, J. (2014). Health related quality of life may increase when patients with a stoma attend patient education-a case-control study. PLOS ONE, 9(3), e90354. https://doi.org/10.1371/journal.pone.0090354

Daudt, H. M., Van Mossel, C., \& Scott, S. J. (2013). Enhancing the scoping study methodology: a large, inter-professional team's experience with Arksey and O'Malley's framework. BMC Medical Research Methodology, 13(1), 48. https://doi.org/10.1186/1471-2288-13-48 
de Jonge, P., Huyse, F. J., Ruinemans, G. M.-F., Stiefel, F. C., Lyons, J. S., \& Slaets, J. P. (2000). Timing of psychiatric consultations: the impact of social vulnerability and level of psychiatric dysfunction. Psychosomatics, 41(6), 505-511. https://doi.org/10.1176/appi.psy.41.6.505

Dear, M. S. (1985). Hospital vs. hospital(ity). Psychosocial Rehabilitation Journal, 9(1), 70. https://doi.org/10.1037/h0099160

Drenth, C. M. (2013). The Lived Experience of a Critical Illness-A Social Worker's Reflection. Illness, Crisis \& Loss, 21(3), 231-245. https://doi.org/10.2190/IL.21.3.e

Eastwood, H. (1993). The social consequences of surgical complications for patients with proximal femoral fractures. Age and Ageing, 22(5), 360-364. https://doi.org/10.1093/ageing/22.5.360

Elliott, P. C., Murphy, B. M., Oster, K. A., Le Grande, M. R., Higgins, R. O., \& Worcester, M. U. (2010). Changes in mood states after coronary artery bypass graft surgery. European $\begin{array}{llll}\text { Journal of } \quad \text { Cardiovascular } & \text { Nursing, } & \text { 9(3), }\end{array}$ https://doi.org/10.1016/j.ejcnurse.2009.11.010

Ensberg, M. D., Paletta, M. J., Galecki, A. T., Dacko, C. L., \& Fries, B. E. (1993). Identifying elderly patients for early discharge after hospitalization for hip fracture. Journal of gerontology, 48(5), M187-M195. https://doi.org/10.1093/geronj/48.5.M187

Epstein, J., Turgeman, A., Rotstein, Z., Horoszowski, H., Honig, P., Baruch, L., \& Noy, S. (1998). Preadmission psychosocial screening of older orthopedic surgery patients: Evaluation of a social work service. Social Work in Health Care, 27(2), 1-25. https://doi.org/10.1300/J010v27n02_01

Fraczyk, L., \& Godfrey, H. (2010). Perceived levels of satisfaction with the preoperative assessment service experienced by patients undergoing general anaesthesia in a day surgery setting. Journal of Clinical Nursing, $19(19 \quad-\quad 20), \quad 2849-2859$. https://doi.org/10.1111/j.1365-2702.2010.03277.x

Gilmartin, J. (2004). Day surgery: patients' perceptions of a nurse - led preadmission clinic. $\begin{array}{llll}\text { Journal of Clinical } & \text { Nursing, } & \text { 243-250. }\end{array}$ https://doi.org/10.1046/j.1365-2702.2003.00836.x

Gorton, A. J., Jayanthi, N. V. G., Lepping, P., \& Scriven, M. W. (2008). Patients' attitudes towards "do not attempt resuscitation" status. Journal of Medical Ethics, 34(8), 624-626. https://doi.org/10.1136/jme.2007.022772

Halfens, R. J. (1995). Effect of hospital stay on health locus-of-control beliefs. Western Journal of Nursing Research, 17(2), 156-167. https://doi.org/10.1177/019394599501700204

Hamilton, J. G., Genoff, M. C., Salerno, M., Amoroso, K., Boyar, S. R., Sheehan, M., ... Salo-Mullen, E. E. (2017). Psychosocial factors associated with the uptake of contralateral prophylactic mastectomy among BRCA1/2 mutation noncarriers with newly diagnosed breast cancer. Breast cancer research and treatment, 162(2), 297-306. https://doi.org/10.1007/s10549-017-4123-x 
Johansson, K., Salanterä, S., \& Katajisto, J. (2007). Empowering orthopaedic patients through preadmission education: results from a clinical study. Patient Education and Counseling, 66(1), 84-91. https://doi.org/10.1016/j.pec.2006.10.011

Lamarche, D., Taddeo, R., \& Pepler, C. (1998). The preparation of patients for cardiac surgery. Clinical Nursing Research, 390-405. https://doi.org/10.1177/105477389800700406

Lepczyk, M., Raleigh, E. H., \& Rowley, C. (1990). Timing of preoperative patient teaching. Journal of Advanced Nursing, 300-306. https://doi.org/10.1111/j.1365-2648.1990.tb01817.x

Levac, D., Colquhoun, H., \& O'Brien, K. K. (2010). Scoping studies: advancing the methodology. Implement Sci, 5(1), 1-9. https://doi.org/10.1186/1748-5908-5-69

Levenson, J. L. (2007). Psychiatric issues in surgical patients part I: General issues. Primary Psychiatry, 14(5), 35.

Mannion, A. F., Elfering, A., Staerkle, R., Junge, A., Grob, D., Dvorak, J., .... Boos, N. (2007). Predictors of multidimensional outcome after spinal surgery. European spine journal, 16(6), 777-786. https://doi.org/10.1007/s00586-006-0255-0

Maramaldi, P., Sobran, A., Scheck, L., Cusato, N., Lee, I., White, E., \& Cadet, T. J. (2014). Interdisciplinary medical social work: A working taxonomy. Social Work in Health Care, 53(6), 532-551. https://doi.org/10.1080/00981389.2014.905817

Mitchell, M. (2010). A patient-centred approach to day surgery nursing. Nursing Standard, 24(44), 40-46. https://doi.org/10.7748/ns2010.07.24.44.40.c7885

Ogilvie, D., Fayter, D., Petticrew, M., Sowden, A., Thomas, S., Whitehead, M., \& Worthy, G. (2008). The harvest plot: a method for synthesising evidence about the differential effects of interventions. BMC Med Res Methodol, 8, 8. https://doi.org/10.1186/1471-2288-8-8

Oxlad, M., Stubberfield, J., Stuklis, R., Edwards, J., \& Wade, T. D. (2006). Psychological risk factors for cardiac-related hospital readmission within 6 months of coronary artery bypass graft surgery. Journal of Psychosomatic Research, 61(6), 775-781. https://doi.org/10.1016/j.jpsychores.2006.09.008

Preyde, M., \& Chapman, T. (2007). Psychosocial profile of elderly patients discharged from a community hospital. Social Work in Health Care, 45(2), 77-95. https://doi.org/10.1300/J010v45n02_05

Querido, A. (1959). Forecast and follow-up an investigation into the clinical, social, and mental factors determining the results of hospital treatment. British journal of preventive \& social medicine, 13(1), 33-49. https://doi.org/10.1136/jech.13.1.33

Rice, V. H., Mullin, M. H., \& Jarosz, P. (1992). Preadmission self-instruction effects on post-admission and postoperative indicators in CABG patients: Partial replication and extension. Research in nursing \& health, 15(4), 253-259. https://doi.org/10.1002/nur.4770150404

Rozas, L. W., \& Klein, W. C. (2010). The Value and Purpose of the Traditional Qualitative Literature Review. Journal of Evidence-Based Social Work, 7(5), 387-399. https://doi.org/10.1080/15433710903344116 


\section{Macrothink}

International Journal of Social Work

ISSN 2332-7278 2018, Vol. 5, No. 1

Schoessler, M. (1989). Perceptions of pre-operative education in patients admitted the morning of surgery. Patient Education and Counseling, 14(2), 127-136. https://doi.org/10.1016/0738-3991(89)90048-7

Shahmansouri, N., Janghorbani, M., Salehi Omran, A., Karimi, A. A., Noorbala, A. A., Arjmandi, A., \& Nikfam, S. (2014). Effects of a psychoeducation intervention on fear and anxiety about surgery: Randomized trial in patients undergoing coronary artery bypass

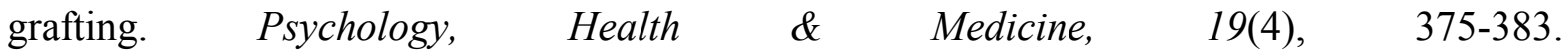
https://doi.org/10.1080/13548506.2013.841966

Sørlie, T., \& Sexton, H. C. (2004). Predictors of change in health locus of control following surgical treatment. Personality and Individual Differences, 36(5), 991-1004. https://doi.org/10.1016/S0191-8869(03)00167-3

Spilsbury, K., Nelson, A., Cullum, N., Iglesias, C., Nixon, J., \& Mason, S. (2007). Pressure ulcers and their treatment and effects on quality of life: hospital inpatient perspectives. Journal of Advanced Nursing, 57(5), 494-504. https://doi.org/10.1111/j.1365-2648.2006.04140.x

Vallis, T. M., \& Leddin, D. (2004). What Makes Crohn's Disease Patients Difficult to Manage? The Role of Psychosocial Factors. Journal of Clinical Psychology in Medical Settings, 11(4), 325-332. https://doi.org/10.1023/B:JOCS.0000045352.14224.78

\section{Copyright Disclaimer}

Copyright reserved by the author(s).

This article is an open-access article distributed under the terms and conditions of the Creative Commons Attribution license (http://creativecommons.org/licenses/by/3.0/). 